\title{
Seroprevalence of Anti-EBV IgG among Various Age Groups from Khon Kaen Province, Thailand
}

\author{
Rabporn Suntornlohanakul, Nasamon Wanlapakorn, Sompong Vongpunsawad, \\ Thanunrat Thongmee, Jira Chansaenroj, Yong Poovorawan*
}

\begin{abstract}
Epstein-Barr virus (EBV) is an extremely common herpesvirus that may cause asymptomatic infection or various diseases, including infectious mononucleosis, certain lymphoproliferative diseases and several types of neoplasms. Vaccine development is an important strategy to reduce the burden of EBV-associated diseases and the timing of vaccinations should be before primary infection occurs. In the past, more than $90 \%$ of Thai children were infected with EBV in early childhood. Now, due to the improved healthcare system in Thailand, we aim to determine current prevalence of EBV infection among people in different age groups. A total of 538 sera were collected from residents of Khon Kaen province in northeastern Thailand for detecting anti-EBV IgG. Sera of infants under 2-years-old were also tested for anti-EBV IgM and EBV-DNA. The prevalence of anti-EBV IgG was 47.1\% (95\% CI: 23.3-70.8) in infants aged 0-6 months, 34.9\% (95\% CI: 23.1-46.7) in those aged 6-24 months, 87.9\% (95\% CI: 79.5-96.3) in children aged 3-5 years and then maintained at above 95\% through adulthood. These seropositivity rates among Thai children remain similar to those found in a previous study conducted 20 years ago. Thai children are still exposed to EBV from an early age. Therefore, a prophylactic vaccine should be given within the first two years of life.
\end{abstract}

Keywords: Seroprevalence - anti-EBV IgG - children - adult - Thailand

Asian Pac J Cancer Prev, 16 (17), 7583-7587

\section{Introduction}

Epstein-Barr virus (EBV), a member of the Herpesviridae family, is a major cause of infectious mononucleosis in young children and adolescents (De Paschale and Clerici, 2012). More than $90 \%$ of the adult population worldwide has antibodies against EBV (Hsu and Glaser, 2000). Once infected, lifelong immunity usually persists. Nevertheless, immune responses are unable to eliminate the virus, resulting in EBV latency in memory B lymphocytes. Clinical manifestations of EBV infections vary according to age, ranging from silent infections in infants to infectious mononucleosis in adolescents and adults. In addition, many serological and molecular studies have provided evidence that EBV is associated with various types of malignancies such as lymphoma, nasopharyngeal carcinoma (NPC), Hodgkin disease and gastric carcinoma (Cohen et al., 2008; Hjalgrim et al., 2000; Mitarnun et al., 2004; Piriou et al., 2012; Tiwawech et al., 2005).

The seroprevalence of EBV antibodies increases with age but varies across populations according to geographic region, ethnicity and socioeconomic status (Balfour et al., 2013; Condon et al., 2014; Dowd et al., 2013; Kagro et al., 1994). In the United States, a seroprevalence survey from 2009 found that around 50\% of children between 6-8 years had antibodies against EBV (Balfour et al., 2013). It was estimated that about half of the infections occurred in late childhood, causing high numbers of infectious mononucleosis cases.

In contrast, an EBV seroepidemiology survey conducted in Thailand from 1997-1998 found that more than $90 \%$ of Thai children between 6-8 years had immunity to the EBV viral capsid antigen (Pancharoen et al., 2001; Poovorawan et al., 1997; Pancharoen et al., 2001). With respect to the improvement of the healthcare system in Thailand during the past decade, we estimated a higher seronegativity rate among infants and young children and designed this study to determine the current status of EBV seroprevalence across age groups. The results of this study will help to identify a target age group for future prophylactic vaccines.

\section{Materials and Methods}

The proposal of this study was approved by the Institutional Review Board of the Faculty of Medicine, Chulalongkorn University (IRB No 526/57). 


\section{Study population}

The sera analyzed in this study were collected in 2014 during research on the impact of universal hepatitis B immunization on newborns as part of the Expanded Program on Immunization (EPI). The age of the subjects ranged from birth to 57 years. All subjects lived in Khon Kaen province in the northeast of Thailand. A total of 538 samples were randomly selected to be used in this study. The subjects had previously been informed by the further study of their sera via written informed-consent.

\section{Laboratory tests}

Serological testing: The sera were stored at $-20 \mathrm{oC}$ at the Center of Excellence in Clinical Virology, Department of Pediatrics, Faculty of Medicine, Chulalongkorn University until used for testing. The presence of anti-EBV-CA (Epstein-Barr virus capsid antigen) IgG was detected by quantitative analysis using commercially-available ELISA kits (EUROIMMUN, Luebeck, Germany) according to the provided instructions. Results were also interpreted according to those instructions. Samples were recorded as seropositive, seronegative or borderline according to levels of anti-EBV-CA IgG being above $22 \mathrm{RU} / \mathrm{ml}$, below $16 \mathrm{RU} / \mathrm{ml}$ or between 16 and $22 \mathrm{RU} / \mathrm{ml}$, respectively. All samples from children under 2 years of age were further tested for anti-EBV-CA IgM using the same, commercially-available ELISA kits. Results of the IgM test were interpreted as positive, negative or borderline according to the included instructions.

\section{Molecular study}

In addition to IgM detection, sera from children under 2 years of age were subjected to viral DNA extraction using an Exgene Viral DNA/RNA kit (GeneAll, Seoul, Korea) according to the manufacturer's instructions . Human herpesvirus DNA was amplified using nested consensus primers for herpes viruses as previously published (Sakulwira et al., 2004). The polymerase chain reaction (PCR) conditions were the same as in the previous study (VanDevanter et al., 1996) and the final PCR products were identified by electrophoresis in $2 \%$ agarose gel (FMC Bioproducts, Rockland, ME). The positive control was a tissue biopsy (nasopharyngeal carcinoma tissue) positive for EBV. The sensitivity of this method to detect EBV DNA is 100 copies per $100 \mathrm{ng}$ of DNA (VanDevanter et al., 1996).

\section{Data analysis}

Analysis involved dividing sera samples into ten age groups in order to depict the age characteristics of EBV seroprevalence, especially during early childhood. Demographic data were presented in terms of the median, range and percentages. Statistical significance was determined by a $P=0.05$. In addition, we reviewed the previous literature reporting the EBV seroprevalence of various countries in recent years to demonstrate trends of seropositivity across different age groups.

\section{Results}

Of the 538 participants, 267 (49.6\%) were male and
$271(50.4 \%)$ were female. The median age was 13 years and ages ranged from 2 days to 57 years. The overall seropositivity rate, defined by an anti-EBV-CA IgG equal to or above $22 \mathrm{RU} / \mathrm{ml}$, was $87.9 \%$ (95\% CI 85.2-90.7). We interpreted those with borderline (between 16 and $22 \mathrm{RU} / \mathrm{ml}$ ) or negative (below $16 \mathrm{RU} / \mathrm{ml}$ ) ELISA results as seronegative. After organizing the subjects into age groups, the seropositivity rate of anti-EBV IgG in infants under 6 months was $47.1 \%$ (95\% CI 23.3-70.8). Then the rate slightly decreased to $34.9 \%$ (95\% CI 23.1-46.7) among children aged from 6 months to two years. In children 3-5 years of age, the seropositivity rate was significantly increased to $87.9 \%$ (95\% CI 79.5-96.3). Afterward, the rate was maintained at above $95 \%$ through adulthood, as shown in Table 1.

Further tests to detect anti-EBV IgM and EBV DNA in the 80 samples from children less than 2 years of age found that 3 samples $(3.8 \%)$ were positive for $\operatorname{IgM}$ and none were positive for EBV DNA. The 3 samples positive for anti-EBV IgM were from the infants aged 11, 13 and 18 months. The 11-month-old infant was also positive for anti-EBV IgG, whereas only IgM was detected in the 13-month-old and 18-month-old infants.

Table 1. Anti-EBV IgG Seropositivity Status by Commercially Available ELISA kit $(\mathbf{n = 5 3 8})$

\begin{tabular}{lcccl}
\hline & \multicolumn{4}{c}{ EBV Seropositive } \\
\cline { 2 - 5 } Age groups & Number & Number & Percent & 95\% CI \\
\hline 0-6 months & 17 & 8 & 47.1 & $23.3-70.8$ \\
6 months-2 years & 63 & 22 & 34.9 & $23.1-46.7$ \\
3-5 years & 58 & 51 & 87.9 & $79.5-96.3$ \\
6-8 years & 53 & 53 & 100 & - \\
9-11 years & 58 & 56 & 96.6 & - \\
12-14 years & 55 & 53 & 96.4 & - \\
15-20 years & 60 & 59 & 98.3 & - \\
21-26 years & 57 & 55 & 96.5 & - \\
27-40 years & 59 & 58 & 98.3 & - \\
>40 years & 58 & 58 & 100 & - \\
\hline Total & 538 & 473 & 87.9 & $85.2-90.7$ \\
\hline
\end{tabular}

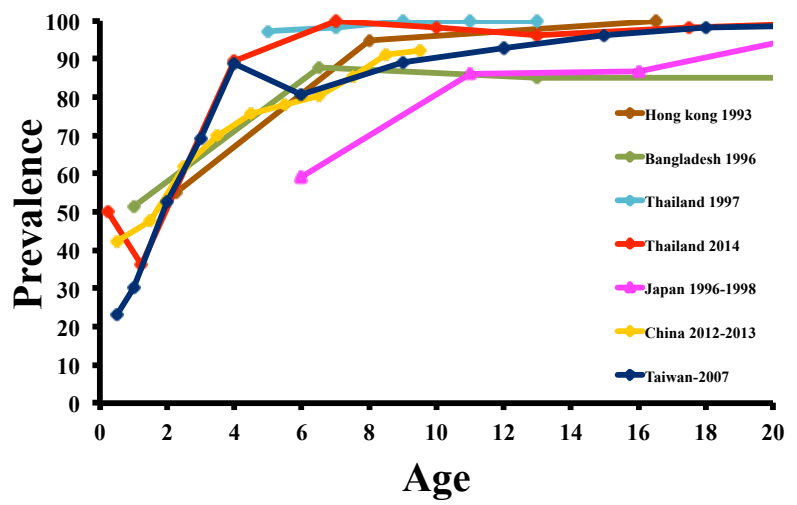

Figure 1. The seroprevalence of EBV Infection in the Asian Countries: Hong Kong (Kangro et al., 1994), Bangladesh (Haque et al., 1996), Thailand in 1997 (Poovorawan et al., 1997), Thailand in 2014 (Current Study), Japan (Takeuchi et al., 2006), China (Xiong et al., 2014) and Taiwan (Chen et al., 2015). The data was Potted by the Mean age in Each Specific Age-Group in the Studies 


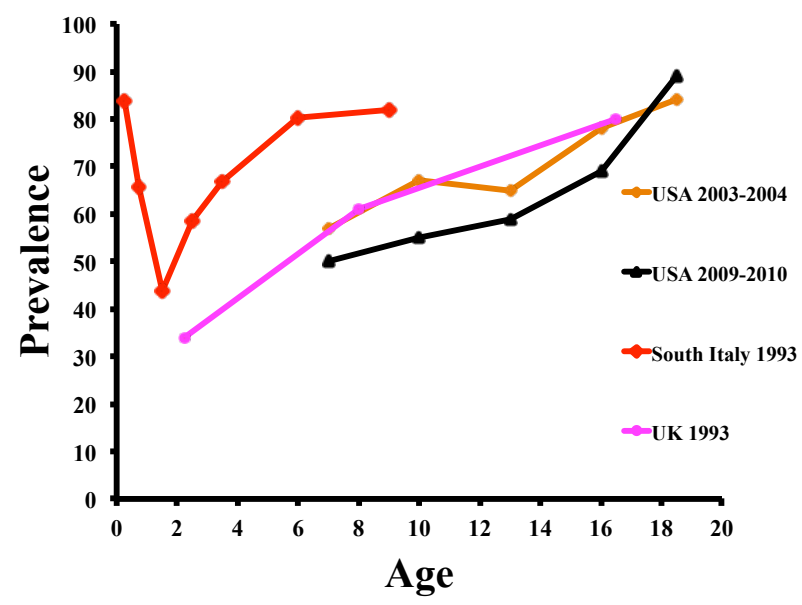

Figure 2. The seroprevalence of EBV Infection in America and Europe Countries: USA in 2003-2004 and 2009-2010 (Balfour et al., 2013), South Italy (Leogrande et al., 1993) and UK (Kangro et al., 1994). The Data was Plotted by the Mean age in Each Specific AgeGroup in the Studies

When we compared our results with reports from other countries in Asia, as shown in Figure1, we found that over $80 \%$ of children at the age of 6 years have antibodies against EBV except in Japan. This is in contrast with the seropositivity rates in the United Kingdom and the United States, where more than $80 \%$ of population were immune by adolescence (Figure 2). The trends in seropositivity rates against $\mathrm{EBV}$ in southern Italy are similar to those found in most Asian countries.

\section{Discussion}

Our study represents an up-to-date, seroepidemiological survey of anti-EBV IgG across 10 age groups in Khon Kaen province, Thailand. Surprisingly, we found that the seropositivity of anti-EBV IgG among 6-8-year-old children hasn't significantly changed from a survey conducted in Bangkok 20 years ago; it was $100 \%$ in this study and $98.3 \%$ in the previous study (Poovorawan et al., 1997). Thus, it is apparent that Thai children are still exposed to EBV from a very young age. Although the habit of feeding babies with pre-chewed food is now less common in Thailand than before, Thai people usually live in large families where infants share eating utensils with other family members. Under these conditions, EBV can easily spread from adults to infants via saliva. In fact, a 1997 study in Bangkok found that home-reared infants below 2 years of age are more likely to contract EBV compared to those who are raised outside their homes (Mekmullica et al., 2003). This pattern of infection is substantially different from, for example, hepatitis A, which has experienced declining seroprevalence due to improvements in sanitation and hygiene (Chatproedprai et al., 2007). Though both infections are related to socioeconomic status, there are different modes of transmission in play. Despite the fact that EBV is easily transmitted via saliva, compared to the fecal-oral route for hepatitis A, its latent phase, when the virus can be secreted in saliva, lasts for a longer period of time.
Interestingly, the seropositivity rate of infants below six months of age was higher than in infants between 6 months and two years: $47.1 \%$ vs. $34.9 \%$. This pattern has also been observed in other studies and is due to preexisting maternal antibodies active in infants under six-months-old (Leogrande et al., 1993). Longitudinal serological data have shown that maternal anti-EBV protection usually lasts for 3-4 months (Biggar et al., 1978; Chan et al., 2001). Once the level of maternal antibodies declines, infants begin to seroconvert. In our study, we observed that the seropositivity rate increased significantly to $87.9 \%$ in children aged 3-5 years. Thus, the majority of children in our study seroconverted during preschool age.

Among the 80 sera of children below two years of age, IgM antibodies were detected in only three samples (3.8\%), collected from children aged 11, 13 and 18 months. The presence of anti-EBV IgM signifies an acute infection or a reactivation of the virus (De Paschale and Clerici, 2012; Nystad and Myrmel, 2007). Since we tested for IgM in young infants, it was very likely that a positive IgM was the result of an acute infection. Thus, our study showed that the earliest age to become infected was 11 months. However, anti-EBV IgM is difficult to detect because its levels decline quickly (Xiong et al., 2014) and it may persist at a very low concentration (Yuan et al., 2013). A previous study reported that the positive rate of EBV-IgM in the acute phase of the disease was only $25 \%$ in infants (Dohno et al., 2010). Therefore, it is possible that some Thai children were infected even before 11 months; we cannot demonstrate the earliest age of primary infection due to the lack of longitudinal data.

The molecular technique is another tool to help diagnose EBV infections with equivocal serological test results. During infectious mononucleosis, EBV virions and naked EBV DNA pass into the peripheral blood and can be detected in serum or plasma samples within 14 days after the onset of symptoms (De Paschale and Clerici, 2012; Kimura et al., 2008). However, EBV DNA can also be detected from reactivated EBV infections (Dohno et al., 2010) and little is known about the EBV DNA prevalence rate in asymptomatic infections. We performed PCR on the 80 sera samples from children under 2 years of age in order to detect acute infections where EBV DNA can be found in peripheral blood before anti-EBV IgG or IgM can be detected. However, no EBV DNA was found in our sera samples. This could have been due to the low viral load of asymptomatic infections, because our small sample size was too small to detect EBV DNA positive patients or because our test was not sensitive enough to detect EBV DNA in the sera samples from infectious mononucleosis (IM) patients. Previous studies have shown that the EBV viral load in EBV-associated IM was approximately $10^{3}$ copies/ugDNA (Cheng et al., 2007). The lower limit of DNA detection in our amplification method was also around $10^{3}$ copies/ugDNA. Therefore, another method, such as real-time PCR, may be more sensitive in detecting EBV DNA from low viral load samples.

While the seroprevalence of anti-EBV IgG in Thailand remained relatively the same during the past 20 years, changes in the prevalence of EBV antibodies in the United States have been observed comparing between 2003-2004 


\section{Rabporn Suntornlohanakul et al}

and 2009-2010 (Figure 2), when the seropositivity rate decreased. In Japan, this declining trend was also reported. This can most likely be explained by smaller household sizes, better hygiene and increased socioeconomic attainment (Takeuchi et al., 2006). Currently, the patterns of seropositivity rates in Japan are changing from that of an Asian country to that of a Western country.

One limitation of our seroepidemiological survey is that it is a cross-sectional study based on only one sample per subject. It is possible that we could have missed a few subjects who had been recently infected but were not yet exhibiting observable levels of anti-EBV IgG at the time of sampling. Another limitation is that our samples were collected from the population of only one province in Thailand. There is a possibility that our data is not representative of EBV seroprevalence in the whole country since EBV seropositivity could be affected by socioeconomic status and family environment (Condon et al., 2014).

In conclusion, our study aimed to investigate the changing trends of Epstein-Barr virus seroprevalence during the past 20 years in Thailand. Surprisingly, it remained about the same. Recent evidence suggests that infection with EBV at an early age increases the risk of developing EBV-related cancer (Piriou et al., 2012). Despite the burden of EBV-associated cancers, vaccine development is still in progress (Balfour, 2014). The Phase II recombinant gp350 vaccine may prevent the development of infectious mononucleosis but cannot prevent asymptomatic infection (Sokal et al., 2007). If a future vaccine aims to prevent infection in Thai children, it should be given within the first two years of life.

\section{Acknowledgements}

This work was supported by National Research University Project, Office of Higher Education Commission (HR1155A, WCU-58-006-HR), The Research Chair Grant NSTDA, The National Research Council of Thailand (NRCT) the Center of Excellence in Clinical Virology, (GCE 58-014-30-004) Chulalongkorn University, Centenary Academic Development Project, Integrated Innovation Academic Center; Chulalongkorn University Centenary Academic Development Project (CU56-HR01); the Ratchadaphiseksomphot Endowment Fund of Chulalongkorn University (RES560530093) the Outstanding Professor of the Thailand Research Fund (DPG5480002); and Chulalongkorn Hospital. Finally, we would like to thank Joshua A. Felber for reviewing this manuscript.

\section{References}

Balfour HH Jr (2014). Progress, prospects, and problems in Epstein-Barr virus vaccine development. Curr Opin Virol, 6, 1-5.

Balfour HH Jr, Sifakis F, Sliman JA, et al (2013). Age-specific prevalence of Epstein-Barr virus infection among individuals aged 6-19 years in the United States and factors affecting its acquisition. J Infect Dis, 208, 1286-93.

Biggar RJ, Henle W, Fleisher G, et al (1978). Primary Epstein-
Barr virus infections in African infants. I. Decline of maternal antibodies and time of infection. Int J Cancer, 22, 239-43.

Chan KH, Tam JS, Peiris JS, et al (2001). Epstein-Barr virus (EBV) infection in infancy. J Clin Virol, 21, 57-62.

Chatproedprai S, Chongsrisawat V, Chatchatee P, et al (2007). Declining trend in the seroprevalence of infection with hepatitis A virus in Thailand. Ann Trop Med Parasitol, 101, 61-8.

Chen CY, Huang KY, Shen JH, et al (2015). A large-scale seroprevalence of epstein-barr virus in taiwan. PLoS One, 10, 115836

Cheng CC, Chang LY, Shao PL, et al (2007). Clinical manifestations and quantitative analysis of virus load in Taiwanese children with Epstein-Barr virus-associated infectious mononucleosis. J Microbiol Immunol Infect, $\mathbf{4 0 ,}$ 216-21.

Cohen JI, Bollard CM, Khanna R, et al (2008). Current understanding of the role of Epstein-Barr virus in lymphomagenesis and therapeutic approaches to EBVassociated lymphomas. Leuk Lymphoma, 49, 27-34.

Condon LM, Cederberg LE, Rabinovitch MD, et al (2014). Agespecific prevalence of Epstein-Barr virus infection among Minnesota children: effects of race/ethnicity and family environment. Clin Infect Dis, 59, 501-8.

De Paschale M, Clerici P (2012). Serological diagnosis of Epstein-Barr virus infection: Problems and solutions. World $J$ Virol, 1, 31-43.

Dohno S, Maeda A, Ishiura Y, et al (2010). Diagnosis of infectious mononucleosis caused by Epstein-Barr virus in infants. Pediatr Int, 52, 536-40.

Dowd JB, Palermo T, Brite J, et al (2013). Seroprevalence of Epstein-Barr virus infection in U.S. children ages 6-19, 2003-2010. PLoS One, 8, 64921.

Haque T, Iliadou P, Hossain A, et al (1996). Seroepidemiological study of Epstein-Barr virus infection in Bangladesh. J Med Virol, 48, 17-21.

Hjalgrim H, Askling J, Sørensen P, et al (2000). Risk of Hodgkin's disease and other cancers after infectious mononucleosis. J Natl Cancer Inst, 92, 1522-8.

Hsu JL, Glaser SL (2000). Epstein-barr virus-associated malignancies: epidemiologic patterns and etiologic implications. Crit Rev Oncol Hematol, 34, 27-53.

Kangro HO, Osman HK, Lau YL, et al (1994). Seroprevalence of antibodies to human herpesviruses in England and Hong Kong. J Med Virol, 43, 91-6.

Kimura H, Ito Y, Suzuki R, et al (2008). Measuring Epstein-Barr virus (EBV) load: the significance and application for each EBV-associated disease. Rev Med Virol, 18, 305-19.

Leogrande G, Jirillo E (1993). Studies on the epidemiology of child infections in the Bari area (south Italy). VII. Epidemiology of Epstein-Barr virus infections. Eur $J$ Epidemiol, 9, 368-72.

Mekmullica J, Kritsaneepaiboon S, Pancharoen C (2003). Risk factors for Epstein-Barr virus infection in Thai infants. Southeast Asian J Trop Med Public Health, 34, 395-7.

Mitarnun W, Pradutkanchana J, Ishida T (2004). Epstein-Barr virus-associated nodal malignant lymphoma in Thailand. Asian Pac J Cancer Prev, 5, 268-72.

Nystad TW, Myrmel H (2007). Prevalence of primary versus reactivated Epstein-Barr virus infection in patients with VCA IgG-, VCA IgM-and EBNA-1-antibodies and suspected infectious mononucleosis. J Clin Virol, 38, 292-7.

Pancharoen C, Bhattarakosol P, Thisyakorn U. Seroprevalence of Epstein-Barr virus infection in Thai children. J Med Assoc Thai, 84, 850-4.

Pancharoen C, Mekmullica J, Chinratanapisit S, et al (2001). Antibody among children in various age groups in Bangkok, 
Thailand. Asian Pac J Allergy Immunol, 19, 135-7.

Piriou E, Asito AS, Sumba PO, et al (2012). Early age at time of primary Epstein-Barr virus infection results in poorly controlled viral infection in infants from Western Kenya: clues to the etiology of endemic Burkitt lymphoma. J Infect Dis, 205, 906-13.

Poovorawan Y, Tantimongkolsuk C, Chongsrisawat V, et al (1997). High prevalence of Epstein-Barr virus antibody among school children of the low to middle socio-economic class in Bangkok, Thailand. Southeast Asian J Trop Med Public Health, 28, 434-5.

Sakulwira K, Theamboonlers A, Oraveerakul K, et al (2004). Orangutan herpesvirus. J Med Primatol, 33, 25-9.

Sokal EM, Hoppenbrouwers K, Vandermeulen C, et al (2007). Recombinant gp350 vaccine for infectious mononucleosis: a phase 2, randomized, double-blind, placebo-controlled trial to evaluate the safety, immunogenicity, and efficacy of an Epstein-Barr virus vaccine in healthy young adults. J Infect Dis, 196, 1749-53.

Takeuchi K, Tanaka-Taya K, Kazuyama Y, et al (2006). Prevalence of Epstein-Barr virus in Japan: Trends and future prediction. Pathol Int, 56, 112-6.

Tiwawech D, Srivatanakul P, Karalak A, et al (2005). Glutathione $\mathrm{S}$-transferase M1 gene polymorphism in Thai nasopharyngeal carcinoma. Asian Pac J Cancer Prev, 6, 270-5.

VanDevanter DR, Warrener P, Bennett L, et al (1996). Detection and analysis of diverse herpesviral species by consensus primer PCR. J Clin Microbiol, 34, 1666-71.

Xiong G, Zhang B, Huang MY, et al (2014). Epstein-Barr virus (EBV) infection in Chinese children: a retrospective study of age-specific prevalence. PLoS One, 9, e99857.

Yuan Huang, Cong Wei, Kun Zheng, et al (2013). The impact of serological features in Chinese children with primary or past Epstein-Barr virus infections. Virol J, 10, 55. 